\title{
"ARQUEOLOGIA E PATRIMÔNIO NO SÉCULO XXI": AS PERSPECTIVAS ABERTAS PELA ARQUEOLOGIA PÚBLICA
}

\author{
Aline Vieira de Carvalho ${ }^{1}$ \\ Pedro Paulo Abreu Funari²
}

\section{Arqueologia para a sociedade}

Desde final da década de 1960, um grande número de intelectuais vinculados tanto à Arqueologia como à Museologia se dedicam a repensar as bases de suas ciências com o intuito de promover ações sociais efetivas e transformadoras. Para os museus, desde o movimento da Nova Museologia, almeja-se a criação de espaços convidativos e, principalmente, propiciadores da construção de um conhecimento crítico e pluralista, capaz de sustentar a existência da cidadania e da democracia; conceitos amplos, cujas definições variam no tempo e no espaço. Nos debates atuais sobre as configurações dos museus, pesquisadores procuram solucionar questões sobre como transformar essas instituições em espaços que valorizem a autonomia, a comunicação, a democratização das memórias, entre outros temas.

A Arqueologia passa por um processo semelhante de reflexões sobre sua própria existência. Esse movimento interno, que ocorre desde a década de 1970, influenciado tanto por teorias pós-processualistas como por teorias marxistas, gerou a fundação de uma nova visão sobre os papéis da ciência arqueológica; criou-se o conceito de Arqueologia Pública (AP). O nome em é composto por uma redundância intencional. Isso porque, para um grande número de defensores da Arqueologia Pública, toda Arqueologia, independente de seu recorte temático ou escolhas teóricometodológicas, deveria ser, em essência, pública. E, nesse viés, encontramos a primeira dificuldade: como definir o que é o público.

Para o arqueólogo britânico Nick Merriman, desde o século XIX, estamos acostumados a assistir aos financiamentos estatais de trabalhos arqueológicos (Merriman, 2004:3). Motivados pelo interesse de construir e

\footnotetext{
${ }^{1}$ Pesquisadora colaboradora e pós-doutoranda no Núcleo de Estudos Estratégicos (NEE - Unicamp). e-mail: alinev99@yahoo.com.br

2 Professor Titular do Departamento de História, Coordenador do NEE/Unicamp. e-mail: ppfunari@uol.com.br
} 
fortalecer identidades nacionais, os Estados vinculavam-se às pesquisas acadêmicas apoiando seus desenvolvimentos, através dos museus ou, posteriormente, das universidades (Bastos e Funari, 2008: 1128). O custeio destas pesquisas com fundos públicos, por si só, poderia transformá-las em algo público.

Acreditar, no entanto, que o sustento estatal seria suficiente para transformar uma pesquisa arqueológica em trabalho de Arqueologia Pública (AP) é uma premissa bastante reducionista. Desde a década de 1970, arqueólogos passaram a se indagar sobre as funções sociais da Arqueologia e, principalmente, sobre como deveriam se estabelecer as relações entre os acadêmicos, suas investigações e a sociedade como um todo. A obra Public Archaeology (1972), do arqueólogo norte-americano Charles Robert McGimsey, professor de Antropologia da Universidade da Lousiana, é considerada um marco na inauguração deste novo campo da Arqueologia (Merriman, 2004:3).

A AP, portanto, é uma área da Arqueologia voltada para o interesse público em geral (Merriman, 2004: 2). Existem diversas vertentes de teorias e práticas dentro deste campo. O que tange todas essas discussões é a reflexão sobre como as pesquisas arqueológicas, realizadas dentro das academias ou mesmo pelas empresas de Arqueologia, se relacionam com a sociedade.

\section{O contexto de formação da Arqueologia Pública Brasileira}

O processo de redemocratização política no Brasil, em meados da década de 1980, foi crucial para a consolidação da AP no país. Com o fim da violência e da censura, pesquisadores puderam criar novos espaços de comunicação entre eles, suas práticas arqueológicas e a sociedade em que estavam inseridos. Apesar das ações da AP brasileira se intensificarem na década de 1980, nas primeiras décadas do século XX, já havia defensores do patrimônio, de sua divulgação e interligação com a sociedade.

As tentativas de defesa do patrimônio arqueológico brasileiro começaram na década de 1920. Naquele momento, o presidente da Sociedade Brasileira de Belas Artes e chefe do Museu Nacional do Rio de Janeiro, Alberto Childe, propunha a nacionalização das "fontes culturais" (Bastos e Funari, 2008: 1128). A iniciativa não foi aprovada pelo Congresso, isto porque, a ação poderia significar a necessidade da nacionalização de propriedades privadas. Atitude nada interessante para os políticos do período. 
A proposta de 1920 não assinalava a necessidade de uma divulgação ou de um programa educacional acerca dos patrimônios. Essa preocupação surgiu apenas em 1935, período anterior à fundação do SPHAN (Serviço do Patrimônio Histórico e Artístico Nacional). Naquele ano, Raimundo Lopes, arqueólogo maranhense, publicou um estudo sobre as fontes culturais nacionais e sobre a necessidade da elaboração de programas educacionais e da divulgação de informações sobre sítios arqueológicos (Bastos e Funari, 2008: 1128).

Mesmo com a publicação de Lopes, o grande passo para a preservação do patrimônio arqueológico nacional só seria dado na década de 1960. Uma comissão formada por arqueólogos, pesquisadores da PréHistória, conquistou a elaboração da lei n. 3924/61, aprovada pelo congresso em 1961. O maior objetivo da lei era definir o patrimônio arqueológico, regularizar sua propriedade e seus usos (Bastos e Funari, 2008: 1128).

Nela ficava estabelecida a guarda e proteção do patrimônio arqueológico pelo Poder Público. Por isso, a realização das escavações, tanto em terras públicas como nas particulares, só poderia acontecer mediante a permissão do Governo da União. As licenças para os trabalhos arqueológicos eram emitidas pela Diretoria do Instituto do Patrimônio Histórico e Artístico Nacional (IPHAN). Proibia-se ainda a exploração comercial dos vestígios culturais, bem como sua destruição ou mutilação (Ojeda: sd). As preocupações com a divulgação das escavações arqueológicas, assim como os programas de educação patrimonial, não estão presentes na lei n. 3924/61.

Os debates sobre esses temas só voltariam ao centro do cenário político-acadêmico brasileiro após 1985. A abertura política do país foi acompanhada pela elaboração de legislações estaduais de proteção dos sítios, monumentos e coleções arqueológicas (Bastos e Funari, 2008:1129), bem como pelo inicio das discussões sobre a Arqueologia Pública. No contexto internacional, no ano de 1986, surgia o Congresso Mundial de Arqueologia, cujas discussões se voltavam para os aspectos sociais da disciplina. Entender as relações entre essa ciência e a sociedade tornava-se um dos pilares desse novo campo de atuação.

Entre os anos de 1961 e 1985, ocorreram inúmeras iniciativas de divulgação do conhecimento arqueológico no país. Essas ações, na maioria das vezes, estavam atreladas aos museus, como é o caso do Museu Imperial, em Petrópolis, Rio de Janeiro (Soares, 2005:20). Apesar da existência de uma preocupação em mostrar ao público o trabalho arqueológico brasileiro, 
apenas a partir da segunda metade da década de 1980, passou-se a refletir sobre os métodos, práticas, valores e significados dessa divulgação. Nascia, então, a AP brasileira.

Arqueólogos da academia, junto com arqueólogos das empresas privadas (recém-inauguradas), inseridos nas discussões sobre a AP nos Estados Unidos e na Europa, fundaram novos museus com suas vertentes educacionais (um exemplo seria o Museu de Arqueologia e Etnologia MAE/USP, fundado em 1989). Além disso, foram planejadas ações inseridas nos trabalhos de campo da Arqueologia, voltadas para o envolvimento das comunidades com os vestígios materiais escavados e suas posteriores preservações e divulgações.

Mesmo que haja atividades em AP no presente momento, ainda se configura como emergencial a elaboração de outras ações e práticas neste campo. A pesquisa realizada por Ana Pinõn, mestra pela Universidade Complutense de Madrid, comprova essa necessidade. Ao indagar 821 alunos do Ensino Fundamental de escolas públicas, nos primeiros anos do século XXI, espalhados por todo Brasil, sobre quem eram os donos dos patrimônios nacionais, Pinõn recebeu $2 / 3$ das respostas afirmando que os patrimônios pertenciam à "donos" específicos, fossem eles pessoas ou instituições (Pinõn e Funari, 2007: 298). Os estudantes não conseguiam identificar relações e aproximações entre os patrimônios e eles próprios.

Saul Milder, arqueólogo brasileiro e professor da Universidade Federal de Santa Maria, atestou a mesma situação no sul do país. Em um trabalho de consultoria realizado pelo Laboratório de Estudos e Pesquisas Arqueológicas (LEPA), da Universidade Federal de Santa Maria (UFSM), para a Empresa de transmissão do Alto Uruguai (ETAU), Milder afirma que: "Chamou a atenção do grupo, durante o processo < de salvamento arqueológico $>$, que muitos habitantes da região com as quais se fazia contato, ficavam absolutamente admirados e, em muitas ocasiões, simplesmente não compreendiam o que se estava realizando. Demonstravam um desconhecimento daquilo que, mesmo ignorado, fazia parte do seu cotidiano" (Milder, 2005:3).

O distanciamento entre a sociedade e seus diversos patrimônios pode ser superado através de ações sólidas da Educação patrimonial. Não se almeja atribuir à sociedade um conhecimento enciclopédico sobre quais são seus patrimônios, datas de fundação, autores, características físicas, entre outros dados. Ao contrário, a Educação patrimonial deve agir no sentido de, democraticamente, construir diálogos entre a sociedade e seus patrimônios. 
Estes diálogos devem ser constituídos para "permitir a realização de conexões entre a vida cotidiana das pessoas com o processo histórico relatado. Devem providenciar instrumentos para a reflexão" (Vargas e Sanoja, 1990:53). Assim, cada grupo social torna-se capaz de atribuir significados ao próprio patrimônio e ao bem público como um todo. Têmse um cidadão crítico pronto para a preservação e, principalmente, para transformação tanto de seu entorno como da sociedade.

\section{A Arqueologia Pública Democrática e a cidadania: o dever da educação patrimonial}

Em outubro de 1990, o Comitê Internacional para a Gestão do Patrimônio Arqueológico (ICAHM - ICOMOS) publicou a Carta de Proteção e Gerenciamento do Patrimônio Arqueológico. O texto, redigido de forma bastante genérica, e direcionado aos profissionais da área, almejava compor alguns parâmetros e diretrizes para a proteção específica dos vestígios arqueológicos considerados patrimônios.

A definição usada para o patrimônio arqueológico na Carta é bastante ampla. No texto, o patrimônio arqueológico é destacado como composto por patrimônios materiais passíveis de serem lidos ou analisados pela Arqueologia (ICAHM, 1990). De acordo com o texto, o patrimônio arqueológico engloba:

“ (...) las huellas de la existencia del hombre y se refiere a los lugares donde se ha practicado cualquier tipo de actividad humana, a las estructuras y los vestigios abandonados de cualquier índole, tanto en la superficie, como enterrados, o bajo las aguas, así como al material relacionado con los mismos.(...)" (ICAHM, 1990)

Composta por nove artigos, a Carta traz referências específicas ao campo que hoje denominamos como AP. Em primeiro lugar, o texto afirma que a proteção do patrimônio arqueológico deve ser compreendida como obrigação moral e de responsabilidade coletiva (ICAHM, 1990). É dado aos Estados à incumbência de providenciar fundos para embasar as atividades de proteção do patrimônio. A proteção efetiva e cotidiana, no entanto, é responsabilidade do Estado, mas, também, de toda a sociedade.

Para o envolvimento da sociedade nesta tarefa considerada moral, a Carta estabelece a necessidade de prover o público geral de informações acerca do patrimônio. Não são definidos os moldes da Educação patrimonial. A Carta indica que as especificidades locais devem ser sempre respeitadas e, por isso, não existem fórmulas para ação de preservação e de 
educação. O único imperativo proposto pelo texto é o de que o passado deve ser mostrado como multifacetado (ICAHM, 1990).

Parte-se do pressuposto, na Carta, de que só é possível preservar o patrimônio através do conhecimento e da afeição. Ao mostrar um passado múltiplo, composto por diversas identidades e passível de muitas interpretações, seria possível criar um número maior de aproximações entre a sociedade no presente e as imagens do passado, representadas pelo patrimônio. Para a Carta, com a identificação pressupõem-se a preservação.

Contudo, não é sempre que existe a possibilidade de valorização de um imenso leque de identidades relacionadas aos patrimônios, sejam eles arqueológicos ou não. O patrimônio, que é composto por um conjunto de bens de ordem material e imaterial, faz referências às identidades e memórias de diferentes grupos sociais (Soares: 2005). O que pode ser importante e gerador de afeição para um determinado grupo de pessoas, não necessariamente causa a mesma comoção em outro grupo social. Neste sentido, convém a pergunta: seria possível a preservação de um patrimônio por parte de pessoas que não se reconhecem nele?

Como não há reconhecimento entre o indivíduo e o patrimônio e, infelizmente, sentidos ou significados sobre a "coisa pública", a resposta a essa pergunta seria: a princípio, não! E, exatamente por isso, a Educação patrimonial torna-se urgente. Dentro dos princípios da AP Democrática, é preciso construir junto com as comunidades o conceito de patrimônio e de bem público. Apenas quando esses conceitos tiverem sentidos para os indivíduos será possível alcançar uma preservação efetiva dos patrimônios, sejam eles de quaisquer espécies. O indivíduo precisa compreender que esse patrimônio é importante para alguém. Para Funari e Bastos, "através da educação patrimonial o cidadão torna-se capaz de entender sua importância no processo cultural em que ele faz parte, cria uma transformação positiva entre a relação dele e do patrimônio cultural" (Bastos e Funari, 2008: 1131). 


\section{Agradecimentos}

Agradecemos a Flavia Souza, Rossano Lopes Bastos, Geraldo Cavagnari, Lourdes Domínguez, Renata Senna Garraffoni, Richard Hingley, Cornelius Hortolf, Matthew Johnson, Nick Merriman, Saul Milder, João Quartim de Moraes, Ana Piñon, Renato Pinto, Erika Robrahn-González, Mario Sanoja, Michael Shanks, Glaydson José da Silva Helaine Silverman, Christopher Tilley, Iraida Vargas. Mencionamos o apoio institucional do Núcleo de Estudos Estratégicos, FAPESP, CNPq, CAPES. A responsabilidade pelas idéias restringe-se aos autores.

\section{Bibliografia}

Bastos, R. L.; Funari, P. P. A. "Public Archaeology and Management of the Brazilian ArchaeologicalCultural Heritage". Handbook of South American Archaeology. Silverman, Helaine e Isbell, William H. (orgs). New York: Springer, 2008. 1127-1133.

CAVAGNARI, G. L. EUA, a estratégia do Chacal, www.galizacig.com/index.html, 2009.

Freire, P. Educação com prática da liberdade. Rio de Janeiro: Paz e Terra, 1980.

FUNARI, P.P.A. Arqueologia. São Paulo, Contexto, 2003.

Funari, P. P.; Carvalho. A. V. Palmares: ontem e hoje. Rio de Janeiro: Zahar, 2005.

Funari, P. P; Zarankin, A. "Cultura material escolar: o papel da arquitetura." Pro-Posições, Campinas, v. 16, n. 1, p. 135-144, 2005.

FUNARI, P. P. "Rescuing ordinry people's culture: museums, material culture and education in Brazil". The presented past - Heritage, museums and education. Stone, Peter G. e Molyneaux, Brian L. Londres. Routledge, 1994:120-135.

FUNARI, P. P. A. ; DOMÍNGUEZ, L. . La Arqueologia Urbana en América Latina: el caso de Habana Vieja, ciudad arqueológica. Estudos Ibero-americanos, Porto Alegre, v. 28, n. 2, p. 113-124, 2002.

FUNARI, P.P.A. ROBRAHN-GONZÁLEZ, E. Editorial, Arqueologia Pública, 1, 2006.

FUNARI, P. P. A.; SILVA, G. J. . Nota de Pesquisa sobre o Projeto de Pesquisa do Acervo de Arqueologia e Patrimônio de Paulo Duarte 06/03/2007. História e-História, v. 2007, p. 1-25, 2007.

GARRAFFONI, R.S.; FUNARI, P.P.A.; PINTO, R. Os estudos sobre a Antiguidade no Brasil: as contribuições das discussões teóricas recentes, O Imperialismo Romano: novas perspectivas a partir da Bretanha, R. Hingley, São Paulo, Annablume/CAPES, 2009.

HINGLEY, R. O Imperialismo Romano: novas perspectivas a partir da Bretanha. São Paulo, Annablume/CAPES, 2009.

HOLTORF, Cornelius. Archaeology is a brand. Oxford: Archaeopresse, 2007.

HOWARD, Michael. Clausewitz. Oxford, Oxford University Press, 2002.

ICAHM. Carta Internacional para la Gestión del Patrimônio Arqueológico, 1990. Disponível no site: www.international.icomos.org/charters/arch_sp.htm Acesso em: 23/01/2009.

JOHNSON. M. An Archaeology of Capitalism. Oxford: Blackwell, 1996.

MERRIMAN, N. "Introduction - diversity and dissonance in public archaeology". Public Archaeology.

Nick Merriman (org): Londres. Routledge, 2004. 
MILDER, S. E. S. (org). “Apresentação”. Educação patrimonial: Perspectivas. Santa Maria (UFSM): Laboratório de Estudos e Pesquisas Arqueológicas, 2005.

OJEDA, C. A. M. "Lei no 3.924 de 26 de Julho de 1961". Revista do Museu. Disponível no site: www.revistamuseu.com.br/legislacao/patrimonio/3924.htm. (Acesso em: 15/01/2009)

PIÑON, A. C.; Funari, P.P. . "Telling Children about the Past in Brasil”. Telling Children about the Past: an Interdisciplinary Perspective. Galanidou and L. H. Dommasnes (eds.): Ann Arbor: International Monographs in Prehistory, 2007.

QUARTIM DE MORAES, J. L'anti-impérialisme en marche. Nouvel Afrique-Asie, Paris, p. 52 - 54, 01 abr. 2005.

SHANKS, M.; TILLEY, C. Re-Constructing Archaeology. Cambridge, Cambridge University Press, 1987.

SOARES, F. C. "Experiências educativas". Educação patrimonial: Perspectivas. Milder, S. E. S. (org). Santa Maria (UFSM): Laboratório de Estudos e Pesquisas Arqueológicas, 2005.

VARGAS, I.; Sanoja, M. Education and the political manipulation of History in Venezuela, in R.MacKenzie \& p.Stone (eds), The Excluded Past, London, Unwin, 1990: 50-60.

VOLKMER, M. S. “O Lúdico”. Educação patrimonial: Perspectivas. Milder, S. E. S. (org). Santa Maria (UFSM): Laboratório de Estudos e Pesquisas Arqueológicas, 2005. 